OPEN ACCESS

Edited by:

Maggie Lau,

Princeton University, USA

Reviewed by:

Michael Schloter,

Helmholtz Zentrum München,

Germany

John Lawrence Darcy,

University of Colorado Boulder, USA

Katsuhiko Mineta,

King Abdullah University of Science and Technology, Saudi Arabia

*Correspondence:

Ann M. Klein

annmaureenklein@gmail.com;

Jessica L. Green

jlgreen@uoregon.edu

Specialty section:

This article was submitted to

Terrestrial Microbiology,

a section of the journal

Frontiers in Microbiology

Received: 04 February 2016

Accepted: 09 May 2016

Published: 24 May 2016

Citation:

Klein AM, Bohannan BJM, Jaffe DA,

Levin DA and Green JL (2016)

Molecular Evidence for Metabolically

Active Bacteria in the Atmosphere.

Front. Microbiol. 7:772.

doi: 10.3389/fmicb.2016.00772

\section{Molecular Evidence for Metabolically Active Bacteria in the Atmosphere}

\author{
Ann M. Klein ${ }^{1 *}$, Brendan J. M. Bohannan , Daniel A. Jaffe ${ }^{2}$, David A. Levin ${ }^{3}$ and \\ Jessica L. Green ${ }^{1,4 *}$ \\ 1 Institute of Ecology and Evolution, Department of Biology, University of Oregon, Eugene, OR, USA, ${ }^{2}$ Department of \\ Atmospheric Sciences, University of Washington Bothell, Bothell, WA, USA, ${ }^{3}$ Department of Mathematics, University of \\ Oregon, Eugene, OR, USA, ${ }^{4}$ Santa Fe Institute, Santa Fe, NM, USA
}

Bacterial metabolisms are responsible for critical chemical transformations in nearly all environments, including oceans, freshwater, and soil. Despite the ubiquity of bacteria in the atmosphere, little is known about the metabolic functioning of atmospheric bacterial communities. To gain a better understanding of the metabolism of bacterial communities in the atmosphere, we used a combined empirical and model-based approach to investigate the structure and composition of potentially active bacterial communities in air sampled at a high elevation research station. We found that the composition of the putatively active bacterial community (assayed via rRNA) differed significantly from the total bacterial community (assayed via rDNA). Rare taxa in the total (rDNA) community were disproportionately active relative to abundant taxa, and members of the order Rhodospirillales had the highest potential for activity. We developed theory to explore the effects of random sampling from the rRNA and rDNA communities on observed differences between the communities. We found that random sampling, particularly in cases where active taxa are rare in the rDNA community, will give rise to observed differences in community composition including the occurrence of "phantom taxa", taxa which are detected in the rRNA community but not the rDNA community. We show that the use of comparative rRNA/rDNA techniques can reveal the structure and composition of the metabolically active portion of bacterial communities. Our observations suggest that metabolically active bacteria exist in the atmosphere and that these communities may be involved in the cycling of organic compounds in the atmosphere.

\section{Keywords: atmosphere, metabolic activity, rarity, sampling theory, Rhodospirillales}

\section{INTRODUCTION}

Studies of microorganisms in terrestrial, aquatic, and host-associated environments have demonstrated that surveying metabolic activity is key to characterizing the functions of microbial communities (e.g., del Giorgio and Scarborough, 1995; Giorgio et al., 1997; Haglund et al., 2003; Lillis et al., 2009; Peris-Bondia et al., 2011; Baldrian et al., 2012). Yet, little is known about the metabolic activity of microbial communities in the atmosphere, an environment that is intimately connected to all biomes spanning the globe. This lack of knowledge is due to both conceptual and technical limitations. Conceptually, the atmosphere has historically been regarded as a dispersal vector for dead, dormant, or inactive cells instead of as a habitat with actively reproducing microbial life (Womack et al., 2010). Technically, low densities of cells have made it difficult to study the activity of airborne microorganisms in situ (Behzad et al., 2015). But there is evidence 
to suggest that airborne bacteria may be metabolically active. Culture-based analyses of bacteria isolated from clouds have shown that bacteria can transform atmospheric compounds including carbon, nitrogen, and oxidative species (Amato et al., 2007a; Hill et al., 2007; Vaïtilingom et al., 2011, 2013). Research has also demonstrated that aerosolized cultured bacterial cells increase their ribosome production, and thus their protein synthesis potential, when supplied carbon substrates in the lab (Krumins et al., 2014). However, due to biases associated with our inability to cultivate most bacterial taxa, culture-based methods do not provide a comprehensive assessment of bacterial diversity in natural environments. The next step in understanding the metabolic functioning of atmospheric bacteria is to apply cultureindependent methods to atmospheric samples, targeting active cells, in order to learn about their potential functions.

The vast majority of culture-independent microbiology research relies on sequence analysis of rDNA (i.e., rRNA genes), which provides information regarding the total community of cells (including active, dead, and dormant individuals). In contrast, sequence analysis of rRNA in ribosomes (Schippers and Neretin, 2006; Lennon and Jones, 2011; Blazewicz et al., 2013; Womack et al., 2015) provides information regarding the potentially metabolically active cells in a community because ribosomes are more abundant in active than in dormant cells (Fegatella et al., 1998; Kerkhof and Kemp, 1999). Studies that have combined both rDNA and rRNA data have led to a wide range of ecological insights including how microbial communities respond to environmental change (Barnard et al., 2013), which taxa contribute to key biogeochemical processes (Schostag et al., 2015), and what mechanisms shape microbial community assembly (Zhang et al., 2014). An emergent theme from comparative rDNA and rRNA analyses is that the active and total community can be fundamentally different from one another, in both structure and composition. For example, in many environmental systems it is the rare members of the total community that are dominant in the active community (Jones and Lennon, 2010; Campbell et al., 2011; Baldrian et al., 2012; Hugoni et al., 2013; Wilhelm et al., 2014; Zhang et al., 2014). This suggests that using rDNA data alone may lead to an underestimation of the functional importance of rare taxa (Jones and Lennon, 2010; Campbell et al., 2011; Aanderud et al., 2015).

Despite the utility of comparative rRNA/rDNA studies, there are limitations (see Blazewicz et al., 2013) associated with this technique that must be carefully considered in the analysis and interpretation of results. One technical complication encountered in several studies is the occurrence of "phantom taxa", here defined as taxa (operational taxonomic units, aka OTUs) that are only observed in the rRNA sequences but not in the rDNA sequences. This is unexpected because the active community is, by definition, a subset of the total community. The occurrence of phantom taxa has been attributed to differences in sample processing in the laboratory (e.g., cDNA synthesis for rRNA but not rDNA; van Gurp et al., 2013) resulting in the introduction of erroneous base pair changes to rRNA samples but not rDNA samples (Lanzén et al., 2011; Mikkonen et al., 2014; Zhen et al., 2015). This could theoretically lead to a situation where an rDNA gene and its' rRNA would not be similar enough to be grouped in the same OTU. Another potential explanation for the presence of phantom taxa is the combination of insufficient sampling of the total community (as suggested by Kamke et al., 2010; Gaidos et al., 2011) and variation in the level of metabolic activity among taxa. The effects of insufficient sampling and differential activity may be magnified by two factors. First, taxa that are rare in the rDNA community have been observed to be disproportionately active relative to abundant members (Campbell et al., 2011; Hugoni et al., 2013; Hunt et al., 2013). Second, it is more difficult to detect rare taxa in the total (rDNA) community compared to the active community because metabolically active cells may contain 100s-1000s of ribosomes (Bremer and Dennis, 1996; Fegatella et al., 1998) but only 1-15 rDNA gene copies (Klappenbach et al., 2001). These factors - in isolation or in combination - could contribute to the observation of phantom taxa.

In this study, we applied comparative $16 \mathrm{~S}$ rDNA and rRNA sequence analyses to characterize the structure and composition of the active and total bacterial communities in the atmosphere. We then used a model-based approach to explore how sampling affects differences in the composition of rRNA and rDNA communities and to assess the likelihood that the presence of phantom taxa is an artifact of sampling. We focused our study on bacteria because they are abundant in the atmosphere [concentration range from $10^{4}$ to $10^{5}$ cells $/ \mathrm{m}^{3}$ (Burrows et al., 2009)] and, due to their small size, can have atmospheric residence times that are long enough for growth and reproduction to occur (Womack et al., 2010). Our study site is located at a high elevation research station on the summit of Mt. Bachelor, Oregon. Mt. Bachelor is an ideal site for studying the potential activity of airborne microbial communities. Due to the geography of the mountain and the surrounding topography, the summit (elevation $2.8 \mathrm{~km}$ above sea level) regularly encounters air masses from the free troposphere, making it possible to collect cells which have been aloft in the atmosphere for over 1 week (Weiss-Penzias et al., 2006). By collecting cells that have been in the atmosphere for extended periods of time, the active community should more closely reflect the activity of cells in the atmosphere and not activity in potential local source environments such as water or soil. To gain a better understanding of the potential functions of bacterial communities in the atmosphere, we asked the following questions: What is the diversity and composition of rRNA and rDNA airborne bacterial communities, and how do they compare? Is metabolic activity correlated with taxa abundance? Does sampling theory explain differences in the composition of rRNA and rDNA communities?

\section{MATERIALS AND METHODS}

\section{Sample Collection}

Sampling was conducted over four days (August 13-16, 2013) at the Mt. Bachelor Observatory (MBO; $\left.43.98^{\circ} \mathrm{N}, 121.7^{\circ} \mathrm{W}\right)$, a mountaintop research station, $30 \mathrm{~km}$ WSW of Bend, OR. $\mathrm{MBO}$ is located at the summit of Mt. Bachelor, an inactive 
volcano, at $2763 \mathrm{~m}$ above sea level. At Mt. Bachelor there is a persistent upslope/downslope diurnal flow in summer. This results in exposure to mainly boundary layer from 10:00 am to $8: 00 \mathrm{pm}$ and free tropospheric air from 10:00 pm to 8:00 am (McClure et al., 2016). Aerosol samples were collected using SKC Biosamplers (BioSampler SKC Inc.). Inpingers were filled with $20 \mathrm{~mL}$ of a water-based preservation solution (LifeGuard Soil Preservation Solution, MO BIO Laboratories, Inc.) to prevent DNase and RNase activity and maintain cells in stasis to allow accurate profiling of the rRNA and rDNA communities. Twenty-four impingers were operated in parallel at 12.5 L/min from approximately 8:00 am - 4:00 pm each day. At the end of each day, the sampling liquid from all impingers was pooled and stored at $-20^{\circ} \mathrm{C}$ yielding one sample per day for a total of four samples. Impingers were rinsed with sterile water, wrapped in aluminum foil, sealed with autoclave tape, and sterilized using an electric pressure cooker.

\section{Nucleic Acid Isolation and cDNA Synthesis}

Samples were transported on dry ice to the University of Oregon where the liquid was thawed and filtered through $0.22 \mu \mathrm{m}$ cellulose nitrate filters (Nalgene Analytical Test Filter Funnels, Thermo Fisher Scientific). To control for possible contamination of lab reagents, blank samples were generated by filtering unused, unopened LifeGuard Solution through new, sterile filters. Blanks were processed identically to samples including nucleic acid extraction, cDNA synthesis, barcoding, and sequencing. RNA and DNA were co-extracted from filters using the MO BIO PowerWater RNA Isolation Kit according to the manufacturer's instructions, with the following modifications (MO BIO Laboratories, Inc.). The initial DNase step was omitted. RNA and DNA were eluted in $100 \mu$ l elution buffer (QIAGEN) and then divided in half. One $\sim 50 \mu$ l aliquot was treated with $1 \mu \mathrm{l}$ DNase (DNase I, RNase-free, Thermo Fischer Scientific, Inc.) and the other was treated with $2 \mu$ l RNase (RNase A, DNase and protease-free, Thermo Fischer Scientific, Inc.). Both reactions were incubated at $37^{\circ}$ for $30 \mathrm{~min}$. Reactions were cleaned using the Qiagen MinElute Enzymatic Reaction Cleanup Kit (QIAGEN). DNA was eluted in $100 \mu l$ elution buffer and RNA was eluted in $50 \mu$ l elution buffer.

cDNA was synthesized from the total RNA extract from samples and blanks using the SuperScript II First-Strand Synthesis System (Invitrogen, Life Technologies Corporation) with random hexamers. All RNA was converted into cDNA in seven synthesis reactions and one reverse transcriptase negative control. The seven cDNA reactions for each sample were pooled, cleaned using Qiagen MinElute Enzymatic Reaction Cleanup Kit (QIAGEN), and eluted in $50 \mu$ l elution buffer. To verify all contaminating DNA was destroyed in the DNase reaction, one control reaction without reverse transcriptase was included for each sample. These control reactions failed to amplify by PCR indicating contaminating DNA was destroyed.

\section{Library Preparation and Sequencing}

$16 \mathrm{~S}$ genes (rDNA) and transcripts (rRNA which was converted to cDNA) were amplified using bacterial/archaeal primers 515 forward (5'-GTGTGCCAGCMGCCGCGGTAA- $\left.3^{\prime}\right)$ and 806 reverse (5'-GGACTACHVGGGTWTCTAAT- $\left.3^{\prime}\right)$ (Caporaso et al., 2012). The reverse primer also contained a 12 base-pair barcode at the $5^{\prime}$ end in order to assign sequences to samples. PCR reactions were performed in triplicate on each DNA and cDNA sample. Each $25 \mu \mathrm{l}$ reaction contained $0.25 \mu \mathrm{l}$ Phusion Hot Start II DNA polymerase (Life Technologies Corporation) $5 \mu \mathrm{l} \mathrm{HF}$ buffer, $0.5 \mu \mathrm{l} 10 \mathrm{mM}$ dNTPs (New England Biolabs, Inc.) $0.5 \mu \mathrm{l}$ forward primer $(10 \mu \mathrm{M})$, and $0.5 \mu \mathrm{l}$ reverse primer $(10 \mu \mathrm{M}), 13.25 \mu \mathrm{H} \mathrm{H}_{2} \mathrm{O}$, and $5 \mu \mathrm{l}$ template. PCR cycling conditions were as follows: initial denaturation at $98^{\circ} \mathrm{C}$ for $90 \mathrm{~s}$ followed by 35 cycles at $98^{\circ} \mathrm{C}$ for $20 \mathrm{~s}, 52^{\circ} \mathrm{C}$ for $30 \mathrm{~s}$ and $72^{\circ} \mathrm{C}$ for $30 \mathrm{~s}$ following by a final extension at $72^{\circ} \mathrm{C}$ for $10 \mathrm{~min}$. Triplicate reactions were pooled, cleaned using the MinElute 96 UF PCR Purification Kit (QIAGEN), and eluted in $20 \mu \mathrm{l}$ elution buffer. The cleaned PCR products were quantitated using a Qubit 2.0 Fluorometer (Invitrogen, Life Technologies Corporation) and combined in equal molar concentrations. The pooled library was concentrated (Zymo Research Clean and Concentrate-5, Zymo Research) and eluted into $50 \mu \mathrm{l}$ elution buffer. PCR products were size fractionated by gel electrophoresis (2\%, low-melt agarose). Products in the range of 250-350 bp were excised, and DNA from the excised gel was extracted (Qiagen MinElute Gel Extraction, QIAGEN) and eluted into $30 \mu$ l elution buffer. The eluate was cleaned a final time (Zymo Research Clean and Concentrate-5, Zymo Research) and eluted into $30 \mu \mathrm{l}$ elution buffer. The final library was quantitated and diluted from 59.42 to $10 \mathrm{nM}$. The amplicon library was sequenced (300 base pairs, single-end) on the Illumina MiSeq platform at the Dana-Farber Cancer Institute Molecular Biology Core (Boston, MA, USA).

\section{Sequence Processing}

Sequences were processed using QIIME version 1.8 (Caporaso et al., 2010) and the UPARSE pipeline (USEARCH version 7.0.1090) (Edgar, 2013). Briefly, libraries were demultiplexed in QIIME using the split_libraries_fastq.py without quality filtering or trimming. Sequences in fastq output from QIIME were quality filtered and trimmed using the fastq_filter USEARCH script. Sequences were trimmed to $296 \mathrm{bp}$. Sequences with a maximum expected error (fastq_maxee) $>0.5$ were removed. Sequences that only occurred once (i.e., singletons) were removed using the derep_fulllength and sortbysize USEARCH scripts. Sequences were clustered into OTUs at $97 \%$ sequence similarity using the UCLUST algorithm (Edgar, 2010). Representative sequences from each OTU were screened for chimeras using the uchime_ref script against the ChimeraSlayer reference database (Broad Microbiome Utilities ${ }^{1}$ version microbiomeutil-r20110519). Headers for representative sequences were reformatted and sequences were numbered sequentially using the fasta_number.py script. Sequences were

\footnotetext{
${ }^{1}$ http://microbiomeutil.sourceforge.net/
} 
mapped to OTUs using the usearch_global script. The resulting OTU map was converted to a tab-delimited OTU table using a modified version of the uc2otutab.py script. The tab-delimited OTU table was converted to BIOM (McDonald et al., 2012) format. Taxonomy was assigned to representative sequences using the RDP Naïve Bayesian Classifier (Wang et al., 2007) against the Greengenes database ${ }^{2}$ (version 13_5) in QIIME.

OTUs for which relative abundance in control samples was significantly correlated with their relative abundance in air samples were removed using the filter_otus_from_otu_table.py script in QIIME. Of the 90 OTUs that were removed, 26 could not be taxonomically classified. Additionally, all OTUs identified as belonging to the class "Chloroplast" (2,612 sequences, 16 OTUs) or family "Mitochondria” (1,021 sequences, 9 OTUs) were removed using the filter_taxa_from_otu_table.py script.

\section{Statistical Analyses and Data Availability}

All statistical analyses were conducted in R (R Core Team, 2016) primarily using the packages vegan (Oksanen et al., 2016) and BiodiversityR (Kindt and Coe, 2005) for ecological statistics, and the ggplot2 package (Wickham, 2009) for visualizations. All analyses of beta-diversity were based on Canberra distances. DESeq2 (Love et al., 2014) implemented in QIIME was used to analyze differential abundance of OTUs between the rRNA and rDNA communities. Sequence files and metadata have been deposited in Figshare ${ }^{3}$.

\section{Sampling Model}

Sampling models have been widely used in ecology as a tool to understand diversity patterns in communities (Gotelli and Colwell, 2001). Building on this body of literature, we developed sampling theory regarding the joint distribution of rDNA and rRNA in order to gain insights into the effects of sampling on observations of rDNA and rRNA taxa. In brief (details are provided in the Data Sheet S1), we specified the joint distribution by first identifying the taxa-abundance distribution for rDNA, and second, the conditional abundance of rRNA for a given rDNA abundance. For positive integer $k$, the abundance $k$ refers to those taxa having $k$ individuals in the population. Introducing additional assumptions allows us to identify the conditional abundance of rRNA by providing only the "activity profile" function $\alpha(k)$, the fraction of active (rRNA producing) taxa in (rDNA) with abundance $k$, and the "activity intensity" function $m(k)$, the ratio of rRNA/rDNA for active taxa with abundance $k$ (Figure 1). Thus, the model requires as input a taxa-abundance distribution for rDNA, and the functions $\alpha(k)$ and $m(k)$. The qualitative joint behavior of rDNA and rRNA richness in a random sample of individuals from the community, and in particular the frequency of sample "phantom" taxa (those whose rRNA is represented in the sample but whose rDNA is not), is manifested in the rRNA and rDNA rarefaction curves (plots of the number of taxa as a function of the number of individuals

\footnotetext{
${ }^{2} \mathrm{http}$ //greengenes.secondgenome.com/downloads/database/13_5

${ }^{3}$ https://figshare.com/articles/Sequence_data/2066556
}

sampled) and the curve relating phantom frequency to sampling effort.

\section{RESULTS}

\section{Diversity and Composition of rRNA and rDNA Communities}

Composition of the rRNA and rDNA communities significantly differed [ADONIS, $F(1,6)=1.22, p=0.027$ ] at the level of OTUs and at the order level (Figure 2). The rRNA and rDNA communities were dominated by the orders Actinomycetales, RB41, Saprospirales, Cytophagales, and Rhodospirillales. The relative abundances of the following orders significantly differed between rRNA and rDNA: RB41 $[t(3)=4, p=0.04]$, Saprospirales $[t(3)=6, p=0.01]$, Rhodospirillales $[t(3)=-7$, $p=0.006]$, and Sphingomonadales $[t(3)=10, p=0.002]$. rRNA communities were significantly less variable (as measured by the percentage of shared OTUs) across days than were rDNA communities $(p<0.01)$. rRNA communities shared $28.4 \pm 7.2 \%$ of OTUs ( $16.1 \%$ of the total cDNA sequences) across all four samples, where as rDNA communities shared an average of $17.6 \pm 3.2 \%$ of OTUs. Across all OTUs, relative abundance in the rRNA community was correlated with relative abundance in the rDNA community (Figure 3, Kendall rank correlation coefficient, tau $=-0.078, p=5 \mathrm{e}$ 04). The structure (richness, diversity, and evenness) of the rRNA and rDNA communities also differed. Shannon diversity $[t(3)=10, p=0.002]$ and evenness were significantly greater in the rDNA community $[t(3)=10, p=0.002]$. Richness did not significantly differ $[t(3)=-0.5, p=0.7$, Table 1].

\section{Taxon Abundance and Activity Potential}

Fifty-nine OTUs were identified as differentially abundant (DESeq2, adjusted $p<0.05$ ) between the rRNA and rDNA communities, including 12 OTUs that were more abundant in the rDNA community and 47 that were more abundant in the rRNA community. To identify potentially active taxa, we focused our analysis on OTUs that were shared between the rRNA and rDNA communities and that were overrepresented in the rRNA community (DESeq2, $p<0.01$ ). These are conservative criteria for activity and may exclude taxa that are only moderately active as well as those that, due to sampling, are not found in both the rDNA and rRNA datasets. Using these criteria, 17 OTUs were identified as potentially metabolically active (Supplementary Table S1).

To compare the potential activity of these 17 OTUs to the remainder of the shared OTUs in the community, we plotted the rRNA: rDNA ratios of all shared OTUs against their abundance in the rDNA community. rRNA: rDNA ratios are frequently used as an index of bacterial activity (e.g., Campbell et al., 2011; Baldrian et al., 2012; Zhang et al., 2014) because the number of ribosome per cell is correlated with growth rate in cultured bacterial isolates (Fegatella et al., 1998; Kerkhof and Kemp, 1999; but see Blazewicz et al., 2013). rRNA: rDNA ratios in this study ranged from 0.002 to 122 ; 
A

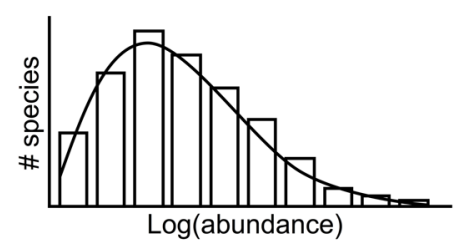

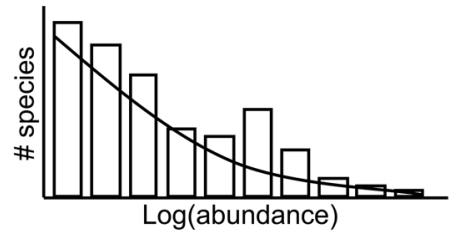

Log(abundance)
Shape of species abundance distribution
B
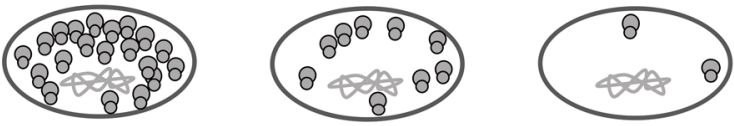

C

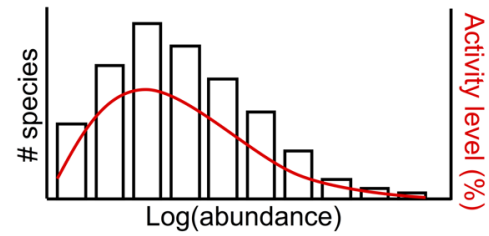

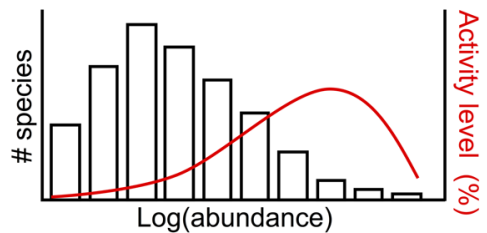

Activity intensity (i.e. RNA:DNA ratio, $m(k)$ )

Activity profile $(\alpha(k))$

FIGURE 1 | Conceptual representation of model parameters for the ecological community that is randomly sampled. (A) Example taxa abundance distributions. The shape of the underlying rDNA taxa abundance distribution can be varied. (B) Bacterial cells with chromosomal DNA and varying number of ribosomes per cell. Activity intensity $(m(k))$, or the number of rRNAs per rDNA, can be constant or vary across rDNA abundance $k$. (C) Example taxa abundance distributions with activity profiles $(\alpha(k))$ shown in red. The activity profile specifies the proportion of active taxa at each abundance $k$. This can be varied such that low abundance values contain a higher proportion of active taxa than high abundant values (left) or vice versa (right).

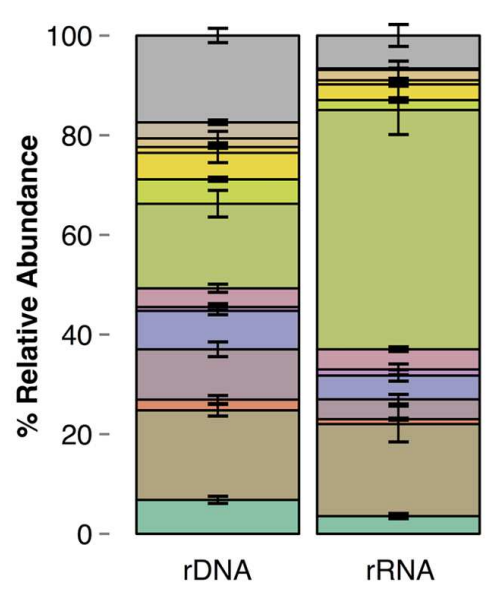

Other order
Bacteria, Other (unclassified)
Bacteria, Proteobacteria, Gammaproteobacteria, Pseudomonadales
Bacteria, Proteobacteria, Deltaproteobacteria, Myxococcales
Bacteria, Proteobacteria, Betaproteobacteria, Burkholderiales
Bacteria, Proteobacteria, Alphaproteobacteria, Sphingomonadales
Bacteria, Proteobacteria, Alphaproteobacteria, Rhodospirillales
Bacteria, Proteobacteria, Alphaproteobacteria, Rhizobiales
Bacteria, Bacteroidetes, Sphingobacteriia, Sphingobacteriales
Bacteria, Bacteroidetes, Cytophagia, Cytophagales
Bacteria, Bacteroidetes, Saprospirae, Saprospirales
Bacteria, Actinobacteria, Thermoleophilia, Solirubrobacterales
Bacteria, Actinobacteria, Actinobacteria, Actinomycetales
Bacteria, Acidobacteria, Chloracidobacteria, RB41

FIGURE 2 | Order-level taxonomic composition of rRNA and rDNA communities. Errors bars are standard deviations.

approximately $63 \%$ of OTUs had rRNA: rDNA ratios less than 1. The taxa with highest rRNA: rDNA ratios were rare members of the rDNA community (Figure 3). Specifically, the rRNA: rDNA ratio was negatively correlated with abundance in the rDNA community (Pearson correlation, $r=-0.11$, $p$-value $<0.05)$.

\section{Sampling Theory and Phantom Taxa}

We used three rarefaction curves (rDNA, rRNA, and phantom taxa, Figure 4) to describe the expected fraction of total taxa appearing in the sample as a function of sampling rate. The rDNA curve converges to 1 at full sampling intensity; the rRNA rarefaction curve converges to the proportion of total taxa which are active. Under sufficient sampling effort, the number of phantom taxa goes to zero. The rate at which the number of phantom taxa goes to zero depends on the model parameters, including the rDNA abundance distribution, intensity function, and activity profile (Figure 1). For example, in communities where the majority of the active taxa are abundant in the rDNA community and activity intensity is 


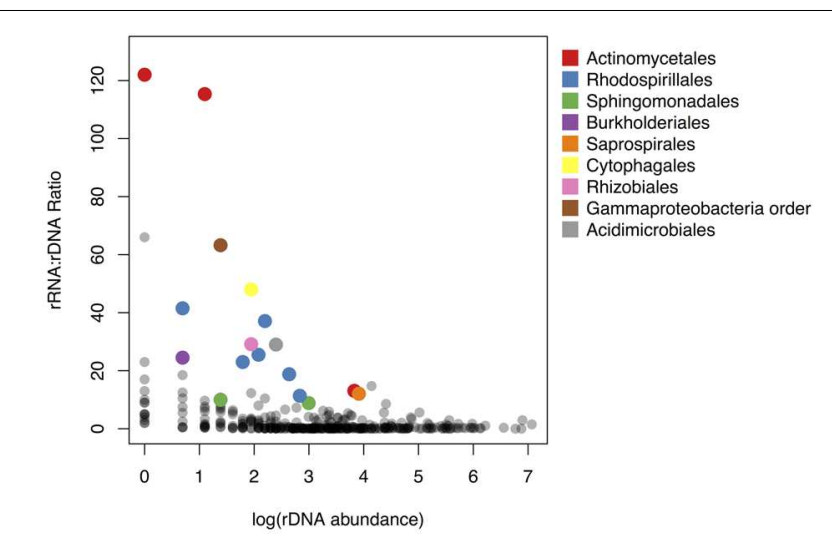

FIGURE 3 | Relationship between rRNA: rDNA ratio and abundance in the rDNA community. rRNA: rDNA ratio is analogous to the activity intensity parameter $(m(k))$ in the sampling model. Colored points represent taxa significantly overrepresented in the active community. Points are colored by taxonomic order.

positively correlated with rDNA abundance (Figure 4, row a), the number of phantoms goes to zero rapidly. In contrast, when active taxa are rare in the rDNA community and activity intensity is negatively correlated with rDNA abundance (Figure 4, row b), the number of phantoms does not decrease as rapidly.

\section{DISCUSSION}

In this study we used comparative $16 \mathrm{~S}$ rDNA and rRNA sequence analyses to ask if there are metabolically active bacteria in the atmosphere. Our results demonstrate that bacteria in the atmosphere contain ribosomes, and some taxa have many more copies of $16 \mathrm{~S}$ ribosomal RNA than they have $16 \mathrm{~S}$ ribosomal genes, suggesting that these taxa may be metabolically active. We found that potential activity level (rRNA: rDNA ratio) varies

TABLE 1 | Sequence summary statistics.

\begin{tabular}{ll}
\hline Category & Count \\
\hline Raw sequences & 594,783 \\
Filtered sequences & 153,088 \\
Mean filtered sequences/sample & $19,136 \pm 7,708.60$ \\
OTUs & 1,144 \\
OTUs after rarefaction & 1,076 \\
Mean OTUs/library & $293.88 \pm 39.21$ \\
OTUs shared across all libraries & 23 \\
OTUs unique to one library & 606 \\
Mean unique OTUs/library & $75.75 \pm 50.26$ \\
rDNA OTUs & 767 \\
rRNA OTUs & 652 \\
OTUs shared between rDNA and rRNA libraries & 343 (31.9\%) \\
OTUs in rDNA but not rRNA libraries & 424 (39.4\%) \\
OTUs in rRNA but not rDNA libraries (phantoms) & 309 (28.7\%)
\end{tabular}

among taxa, resulting in differences in the composition of the rRNA and rDNA communities. Our modeling results support the assumption that differences in the structure and composition of the rRNA and rDNA communities, including the observation of phantom taxa, are due to the sampling of taxa with different levels of activity. Below we explore the composition of rRNA and rDNA communities with a focus on the physiology of potentially active groups, and we conclude with a discussion of the effect of sampling on the observed differences in the rRNA and rDNA communities.

\section{Rhodospirillales Are Abundant in Both the rRNA and rDNA Communities}

Culture-independent tools are making it possible to begin mapping the bacterial composition of the atmosphere on a global scale. While this endeavor remains in its infancy, some general patterns are beginning to emerge. Our rDNA-based bacterial community data is consistent with prior studies and includes several taxonomic orders commonly found in air samples. For example, the Actinomycetales, which were abundant in our samples, are frequently found in the atmosphere (Brodie et al., 2007; Bowers et al., 2013; Gandolfi et al., 2015) and have been found to be abundant in other studies at high elevation sites (Bowers et al., 2012), including MBO (Smith et al., 2013). There are two reasons to expect this order to be abundant in the atmosphere. First, Actinomycetales are abundant and ubiquitous in soil and freshwater (Ventura et al., 2007), and thus there is a large terrestrial source pool. Second, they produce small spores (Reponen et al., 1998), which likely have a long residence time in the atmosphere. We also observed several other taxonomic groups commonly detected in air samples, including Pseudomonadales (Smith et al., 2012), Burkholderiales, and Sphingomonadales (Smith et al., 2013).

One pattern that is unique to our data set is the prevalence of Rhodospirillales. In other studies of airborne bacterial communities, Rhodospirillales have not been found in high relative abundance (Polymenakou et al., 2008; Bowers et al., 2013). One potential mechanism driving the abundance of Rhodospirillales at $\mathrm{MBO}$ could be the nearby marine source. $\mathrm{MBO}$ is approximately $200 \mathrm{~km}$ from the Pacific Ocean, and most air masses travel over the Pacific for several days before reaching the summit (Weiss-Penzias et al., 2006). Atmospheric residence times of marine bacteria collected at $\mathrm{MBO}$ may range from approximately 1 day for cells aerosolized at the coast, to several days for cells aerosolized at more distant locations over the Pacific Ocean. Rhodospirillales are frequently found in marine samples (Feingersch et al., 2010; Yin et al., 2013; Li et al., 2014), and their presence in the atmosphere has been reported in a study of communities in the troposphere ( 8-10 km above sea level; DeLeon-Rodriguez et al., 2013). Researchers found that Rhodospirillales were enriched in samples collected during a hurricane (DeLeon-Rodriguez et al., 2013) suggesting that, under certain conditions, marine bacteria can be aerosolized and reach the upper levels of the atmosphere. 


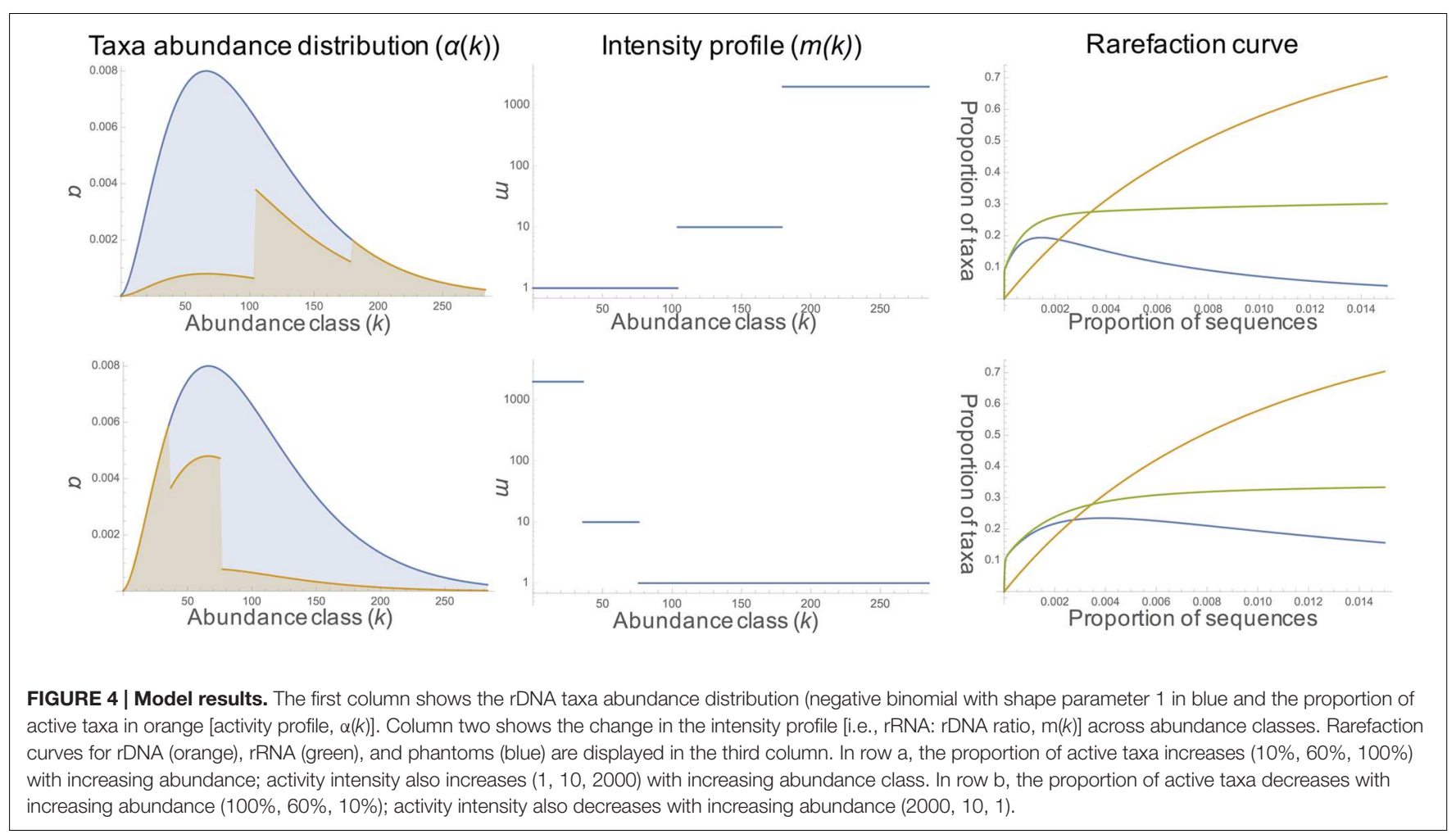

To our knowledge, this is the first rRNA-based analysis of bacteria in the atmosphere. Consistent with what has been reported for other environments, e.g., soil (Baldrian et al., 2012) and water (Wilhelm et al., 2014), we found that the rRNAand rDNA-community composition differed (Figure 1), and our model results demonstrated that observed differences in community composition reflect differences in the metabolic activity among taxa in the atmosphere. Several orders - including RB41 (an uncharacterized order of Acidobacteria), Saprospirales, and Sphingomonadales - were significantly underrepresented in the rRNA relative to the rDNA community and may have reduced activity compared to other taxa. RB41 and Saprospirales are typically found in soils (Janssen, 2006; King et al., 2010), and Saprospirales has also been detected in air samples (Fierer et al., 2008). Sphingomonadales are commonly detected in air samples (Amato et al., 2007b; Bowers et al., 2011; Després et al., 2012) and are abundant on leaf surfaces (Vorholt, 2012). These results suggest that soil and leaf surfaces are likely substantial sources of bacteria in the atmosphere and may shape the composition of the total community, but not necessarily the active community. There was only one order that was significantly more abundant in the rRNA relative to the rDNA community, and this was Rhodospirillales. The potential role of metabolically active Rhodospirillales is discussed below.

\section{Rhodospirillales Are Potentially Active in the Atmosphere}

Of 343 OTUs shared by the rRNA and rDNA datasets (Table 1), 59 significantly differed in abundance. Of those, the 14 OTUs that were more abundant in the rRNA than rDNA community belonged to the family Acetobacteraceae. The Acetobacteraceae are members of the order Rhodospirillales. They are known commonly as the acetic acid bacteria, and their metabolism is characterized by the fermentation of ethanol to acetic acid (Komagata et al., 2014). Ethanol is a common chemical in the atmosphere (Kirstine and Galbally, 2012) with emissions from both biogenic (i.e., plant leaves) and anthropogenic sources (Naik et al., 2010) and is a precursor of ozone and peroxyacetyl nitrate, an eye irritant found in smog. This suggests that bacteria in the atmosphere may be involved in the cycling of compounds that are relevant to human health through the biotransformation of ethanol to acetic acid.

The three Acetobacteraceae OTUs with the greatest difference in abundance between the rRNA and rDNA datasets were all identified by BLAST $(E$-value $<1 \mathrm{e}-100)$ (Altschul et al., 1990) as Acidisphaera rubrifaciens. A. rubrifaciens is an aerobic, chemoorganoheterotroph and facultative phototroph which was originally isolated from an acidic hot spring (Hiraishi et al., 2000). It produces bacteriochlorophyll a and carotenoid pigments, which could protect against UV damage in the atmosphere. Research has shown that optimal growth of A. rubrifaciens occurs in the light with simple organic compounds as energy and carbon sources. More specifically, growth can occur on the conjugate bases of organic acids (Hiraishi et al., 2000) found in the atmosphere, such as fumarate, gluconate, lactate, malate, pyruvate, and succinate (Finlayson-Pitts and Pitts, 1999). It is possible that succinate concentrations were elevated during the time of sampling at the $\mathrm{MBO}$ site, as there were several 
active wildfires in the region, and concentrations of succinic acid are often elevated in the atmosphere during biomass burning (Falkovich et al., 2005; Kundu et al., 2010). Furthermore, microbes isolated from the atmosphere have been shown to degrade organic acids, including succinate, and this biological process may be more important than abiotic chemical cycling (i.e., photodegradation; Vaïtilingom et al., 2011). Therefore, the potential ability of airborne bacteria, such as A. rubrifaciens, to grow using organic acids has implications for biogeochemical cycling in the atmosphere.

\section{Rare Taxa in the rDNA Community Were Disproportionately Active}

We used rRNA: rDNA ratios to assess the metabolic potential of bacterial taxa in the atmosphere. Ratios ranged from 0.002 to 122 with an average of 3.71 across all taxa detected in both the rRNA and rDNA communities. In contrast, studies in other environments including soil (Dlott et al., 2015) and marine systems (Campbell et al., 2011; Campbell and Kirchman, 2013) have reported lower rRNA: rDNA ratios. For example, rRNA: rDNA ratios in marine systems average have been shown to range from 1.1 to 1.6 (Campbell and Kirchman, 2013), and ratios as high as 10.8 have been reported for a single taxon (Brettar et al., 2012). This suggests that, on average, bacteria in the atmosphere have the same potential for metabolic activity as bacteria in other habitats and may be more active both in terms of the portion of active taxa and the specific activity of individual taxa.

Across all OTUs, abundance in rDNA was correlated with abundance in rRNA. However, OTUs with the highest rRNA: rDNA ratios were all rare members of the rDNA community. In other words, the potential activity of these OTUs was negatively related to abundance in the rDNA community (Figure 3). This pattern has been observed in other environments including marine (Campbell et al., 2011; Hugoni et al., 2013; Hunt et al., 2013), freshwater (Wilhelm et al., 2014), and soil systems (Gremion et al., 2003). Across environments, the bacterial taxa which contribute to ecosystem functioning appear rare in rDNA-based surveys, so their importance may not be recognized. This highlights the importance of rRNAbased surveys for linking microbial community composition to ecosystem function, particularly in relatively uncharacterized environments such as the atmosphere.

\section{Disproportionate Activity of Rare Taxa Drives the Occurrence of Phantom Taxa}

Comparative analysis of $16 \mathrm{~S}$ rRNA and rDNA genes is a useful technique for characterizing the potentially active bacterial community. However, there are a number of caveats which must be considered, such as the fact that ribosome content is not always correlated with growth rate (Blazewicz et al., 2013) and that dormant individuals can contain ribosomes (although generally fewer than active cells; Segev et al., 2012). The interpretation of results using a comparative rRNA/rDNA approach can be further complicated by the observation of phantom taxa. Our model demonstrates that the observation of phantom taxa (which comprised $28.7 \%$ of OTUs in this study) is a consequence of sampling stochasticity; rRNA belonging to an active taxon may be included in the sample, while its rDNA avoids collection. Increased sampling of the rDNA community reduces the number of phantom taxa, but the rate at which this occurs depends on the relationship between abundance in the rDNA community and activity level and abundance in the rRNA community. Taxa that are rare in the rDNA community have been shown in a variety of environments to be disproportionately active relative to abundant taxa (Jones and Lennon, 2010; Campbell et al., 2011; Baldrian et al., 2012; Hugoni et al., 2013; Zhang et al., 2014; Wilhelm et al., 2014), and this can contribute to the observation of phantom taxa when using comparative rRNA/rDNA approaches. Based on our model, future comparative rRNA/rDNA studies should consider the expected shape of the rDNA species abundance distribution (SAD), activity intensity and activity profile. Since estimating these metrics is often the goal of rRNA/rDNA sequencing, it may be useful to first obtain these data from a subset of samples. Then, our model could be used to estimate the depth of sampling necessary to reduce the number of phantoms below any prescribed threshold at different activity profiles and intensity functions.

\section{CONCLUSION}

Airborne metabolically active bacteria may alter the chemistry of the atmosphere through the biogeochemical cycling of organic compounds. However, little is currently known regarding which taxa may be active and their potential functions. Our study represents the first to use both rRNA- and rDNA-based methods to identify potentially active bacteria in the atmosphere. We found that the structure and composition of the rRNA and rDNA communities differed, and the rRNA community was characterized by the presence of a few highly active taxa and many taxa with low activity levels. Taxa that were rare in the rDNA community were the most likely to be metabolically active. Consistent with our empirical data, our model results demonstrated that compositional differences between the rRNA and rDNA communities, including the observation of phantom taxa, could be attributed to random sampling and differences in the activity of taxa and their abundance in the rDNA community.

Using combined rRNA/rDNA sequencing, we were able to identify potentially active taxa in the atmosphere including members of the order Rhodospirillales, specifically A. rubrifaciens. A. rubrifaciens may be well-suited for growth in the atmosphere because it has pigments that can mitigate UV damage and because it grows well on simple organic compounds commonly found in the atmosphere. We suggest future research should combine both culture-independent and culture-dependent approaches to assess the potential activity of bacteria in the atmosphere. Culture-independent approaches could be used to identify potentially active taxa and then culture-dependent methods could be used to isolate organisms and study their physiology under various conditions (possibly using aerosolization chambers as in Krumins et al., 2014). 
We also suggest that future studies incorporate sampling through time, particularly over diurnal and seasonal time scales, to gain a better understanding of the relative roles of different environmental variables in structuring the communities. As with any environment, understanding both the structure and function of microbial communities in the atmosphere is needed to assess their potential impact on ecosystem processes such as carbon cycling. This study opens the door for future investigations of the diversity and function of bacterial communities in the atmosphere.

\section{AUTHOR CONTRIBUTIONS}

$\mathrm{AK}, \mathrm{BB}, \mathrm{DJ}, \mathrm{DL}$, and JG designed the experiments. AK and DL performed the experiments. DL contributed new analytic tools. AK and DL analyzed the data. AK, DL, and JG wrote the manuscript. $\mathrm{AK}, \mathrm{BB}, \mathrm{JL}$, and DJ, JG reviewed drafts of the manuscript.

\section{REFERENCES}

Aanderud, Z. T., Jones, S. E., Fierer, N., and Lennon, J. T. (2015). Resuscitation of the rare biosphere contributes to pulses of ecosystem activity. Front. Microbiol. 6:24. doi: 10.3389/fmicb.2015.00024

Altschul, S. F., Gish, W., Miller, W., Myers, E. W., and Lipman, D. J. (1990). Basic local alignment search tool. J. Mol. Biol. 215, 403-410. doi: 10.1016/S00222836(05)80360-2

Amato, P., Demeer, F., Melaouhi, A., Fontanella, S., Martin-Biesse, A.-S., Sancelme, M., et al. (2007a). A fate for organic acids, formaldehyde and methanol in cloud water: their biotransformation by micro-organisms. Atmospheric Chem. Phys. 7, 4159-4169. doi: 10.5194/acp-7-4159-2007

Amato, P., Parazols, M., Sancelme, M., Laj, P., Mailhot, G., and Delort, A.-M. (2007b). Microorganisms isolated from the water phase of tropospheric clouds at the Puy de Dôme: major groups and growth abilities at low temperatures. FEMS Microbiol. Ecol. 59, 242-254. doi: 10.1111/j.1574-6941.2006. 00199.x

Baldrian, P., Kolařík, M., Stursová, M., Kopecký, J., Valášková, V., Větrovský, T., et al. (2012). Active and total microbial communities in forest soil are largely different and highly stratified during decomposition. ISME J. 6, 248-258. doi: 10.1038/ismej.2011.95

Barnard, R. L., Osborne, C. A., and Firestone, M. K. (2013). Responses of soil bacterial and fungal communities to extreme desiccation and rewetting. ISME J. 7, 2229-2241. doi: 10.1038/ismej.2013.104

Behzad, H., Gojobori, T., and Mineta, K. (2015). Challenges and opportunities of airborne metagenomics. Genome Biol. Evol. 7, 1216-1226. doi: 10.1093/gbe/evv064

Blazewicz, S. J., Barnard, R. L., Daly, R. A., and Firestone, M. K. (2013). Evaluating rRNA as an indicator of microbial activity in environmental communities: limitations and uses. ISME J. 7, 2061-2068. doi: 10.1038/ismej.2013.102

Bowers, R. M., Clements, N., Emerson, J. B., Wiedinmyer, C., Hannigan, M. P., and Fierer, N. (2013). Seasonal variability in bacterial and fungal diversity of the near-surface atmosphere. Environ. Sci. Technol. 47, 12097-12106. doi: $10.1021 /$ es402970s

Bowers, R. M., McCubbin, I. B., Hallar, A. G., and Fierer, N. (2012). Seasonal variability in airborne bacterial communities at a high-elevation site. Atmos. Environ. 50, 41-49. doi: 10.1016/j.atmosenv.2012.01.005

Bowers, R. M., McLetchie, S., Knight, R., and Fierer, N. (2011). Spatial variability in airborne bacterial communities across land-use types and their relationship to the bacterial communities of potential source environments. ISME J. 5, 601-612. doi: 10.1038/ismej.2010.167

Bremer, H., and Dennis, P. P. (1996). "Modulation of chemical composition and other parameters of the cell by growth rate," in Escherichia coli and Salmonella:

\section{FUNDING}

This research was funded by the University of Oregon, the Alfred P. Sloan Foundation, and the National Institutes of Health (DL, NIH P50 GM098911).

\section{ACKNOWLEDGMENT}

We wish to thank Tom Lomax, the staff at Mt. Bachelor Ski Resort, Jonathan Hee, and Robert Bowers for their support during sampling.

\section{SUPPLEMENTARY MATERIAL}

The Supplementary Material for this article can be found online at: http://journal.frontiersin.org/article/10.3389/fmicb. 2016.00772

Cellular and Molecular Biology, eds F. Neidhardt, R. Curtiss, J. Ingraham, E. Lin, and K. Low (Washington, DC: ASM Press), 1553-1569.

Brettar, I., Christen, R., and Höfle, M. G. (2012). Analysis of bacterial core communities in the central Baltic by comparative RNA-DNA-based fingerprinting provides links to structure-function relationships. ISME J. 6, 195-212. doi: 10.1038/ismej.2011.80

Brodie, E. L., DeSantis, T. Z., Moberg Parker, J. P., Zubietta, I. X., Piceno, Y. M., and Andersen, G. L. (2007). Urban aerosols harbor diverse and dynamic bacterial populations. Proc. Natl. Acad. Sci. U.S.A. 104:299. doi: 10.1073/pnas.0608255104

Burrows, S. M., Elbert, W., Lawrence, M. G., and Pöschl, U. (2009). Bacteria in the global atmosphere - Part 1: review and synthesis of literature data for different ecosystems. Atmospheric Chem. Phys. Dis. 9, 10777-10827. doi: 10.5194/acpd-9-10829-2009

Campbell, B. J., and Kirchman, D. L. (2013). Bacterial diversity, community structure and potential growth rates along an estuarine salinity gradient. ISME J. 7, 210-220. doi: 10.1038/ismej.2012.93

Campbell, B. J., Yu, L., Heidelberg, J. F., and Kirchman, D. L. (2011). Activity of abundant and rare bacteria in a coastal ocean. Proc. Natl. Acad. Sci. U.S.A. 108, 12776-12781. doi: 10.1073/pnas.1101405108

Caporaso, J. G., Kuczynski, J., Stombaugh, J., Bittinger, K., Bushman, F. D., Costello, E. K., et al. (2010). QIIME allows analysis of highthroughput community sequencing data. Nat. Methods 7, 335-336. doi: 10.1038/nmeth.f.303

Caporaso, J. G., Lauber, C. L., Walters, W. A, Berg-Lyons, D., Huntley, J., Fierer, N., et al. (2012). Ultra-high-throughput microbial community analysis on the Illumina HiSeq and MiSeq platforms. ISME J. 6, 1621-1624. doi: 10.1038/ismej.2012.8

del Giorgio, P. A., and Scarborough, G. (1995). Increase in the proportion of metabolically active bacteria along gradients of enrichment in freshwater and marine plankton: implications for estimates of bacterial growth and production rates. J. Plankton Res. 17, 1905-1924. doi: 10.1093/plankt/17.10.1905

DeLeon-Rodriguez, N., Lathem, T. L., Rodriguez-R, L. M., Barazesh, J. M., Anderson, B. E., Beyersdorf, A. J., et al. (2013). Microbiome of the upper troposphere: species composition and prevalence, effects of tropical storms, and atmospheric implications. Proc. Natl. Acad. Sci. U.S.A. 110, 2575-2580. doi: 10.1073/pnas.1212089110

Després, V. R., Huffman, J. A., Burrows, S. M., Hoose, C., Safatov, A. S., Buryak, G., et al. (2012). Primary biological aerosol particles in the atmosphere: a review. Tellus B 64:15598.

Dlott, G., Maul, J. E., Buyer, J., and Yarwood, S. (2015). Microbial rRNA:rRNA gene ratios may be unexpectedly low due to extracellular DNA preservation in soils. J. Microbiol. Methods 115, 112-120. doi: 10.1016/j.mimet.2015.05.027 
Edgar, R. C. (2010). Search and clustering orders of magnitude faster than BLAST. Bioinformatics 26, 2460-2461. doi: 10.1093/bioinformatics/btq461

Edgar, R. C. (2013). UPARSE: highly accurate OTU sequences from microbial amplicon reads. Nat. Methods 10, 996-998. doi: 10.1038/nmeth.2604

Falkovich, A. H., Graber, E. R., Schkolnik, G., Rudich, Y., Maenhaut, W., and Artaxo, P. (2005). Low molecular weight organic acids in aerosol particles from Rondônia, Brazil, during the biomass-burning, transition and wet periods. Atmospheric Chem. Phys. 5, 781-797. doi: 10.5194/acp-5-781-2005

Fegatella, F., Lim, J., Kjelleberg, S., and Cavicchioli, R. (1998). Implications of rRNA operon copy number and ribosome content in the marine oligotrophic ultramicrobacterium Sphingomonas sp. strain RB2256. Appl. Environ. Microbiol. 64, 4433-4438.

Feingersch, R., Suzuki, M. T., Shmoish, M., Sharon, I., Sabehi, G., Partensky, F., et al. (2010). Microbial community genomics in eastern Mediterranean Sea surface waters. ISME J. 4, 78-87. doi: 10.1038/ismej.2009.92

Fierer, N., Liu, Z., Rodríguez-Hernández, M., Knight, R., Henn, M., and Hernandez, M. T. (2008). Short-term temporal variability in airborne bacterial and fungal populations. Appl. Environ. Microbiol. 74, 200-207. doi: 10.1128/AEM.01467-07

Finlayson-Pitts, B. J., and Pitts, J. N. Jr. (1999). Chemistry of the Upper and Lower Atmosphere: Theory, Experiments, and Applications. Cambridge, MA: Academic Press.

Gaidos, E., Rusch, A., and Ilardo, M. (2011). Ribosomal tag pyrosequencing of DNA and RNA from benthic coral reef microbiota: community spatial structure, rare members and nitrogen-cycling guilds. Environ. Microbiol. 13, 1138-1152. doi: 10.1111/j.1462-2920.2010. 02392.x

Gandolfi, I., Bertolini, V., Bestetti, G., Ambrosini, R., Innocente, E., Rampazzo, G., et al. (2015). Spatio-temporal variability of airborne bacterial communities and their correlation with particulate matter chemical composition across two urban areas. Appl. Microbiol. Biotechnol. 99, 4867-4877. doi: 10.1007/s00253014-6348-5

Giorgio, P. A., Prairie, Y. T., and Bird, D. F. (1997). Coupling between rates of bacterial production and the abundance of metabolically active bacteria in lakes, enumerated using CTC reduction and flow cytometry. Microb. Ecol. 34, 144-154. doi: 10.1007/s002489900044

Gotelli, N. J., and Colwell, R. K. (2001). Quantifying biodiversity: procedures and pitfalls in the measurement and comparison of species richness. Ecol. Lett. 4, 379-391. doi: 10.1046/j.1461-0248.2001.00230.x

Gremion, F., Chatzinotas, A., and Harms, H. (2003). Comparative 16S rDNA and 16S rRNA sequence analysis indicates that Actinobacteria might be a dominant part of the metabolically active bacteria in heavy metal-contaminated bulk and rhizosphere soil. Environ. Microbiol. 5, 896-907. doi: 10.1046/j.14622920.2003.00484.x

Haglund, A.-L., Lantz, P., Törnblom, E., and Tranvik, L. (2003). Depth distribution of active bacteria and bacterial activity in lake sediment. FEMS Microbiol. Ecol. 46, 31-38. doi: 10.1016/S0168-6496(03)00190-9

Hill, K. A., Shepson, P. B., Galbavy, E. S., Anastasio, C., Kourtev, P. S., Konopka, A., et al. (2007). Processing of atmospheric nitrogen by clouds above a forest environment. J. Geophys. Res. 112, 1-16. doi: 10.1029/2006JD008002

Hiraishi, A., Matsuzawa, Y., Kanbe, T., and Wakao, N. (2000). Acidisphaera rubrifaciens gen. nov., sp. nov., an aerobic bacteriochlorophyll-containing bacterium isolated from acidic environments. Int. J. Syst. Evol. Microbiol. 50, 1539-1546. doi: 10.1099/00207713-50-4-1539

Hugoni, M., Taib, N., Debroas, D., Domaizon, I., Jouan Dufournel, I., Bronner, G., et al. (2013). Structure of the rare archaeal biosphere and seasonal dynamics of active ecotypes in surface coastal waters. Proc. Natl. Acad. Sci. U.S.A. 110, 6004-6009. doi: 10.1073/pnas.1216863110

Hunt, D. E., Lin, Y., Church, M. J., Karl, D. M., Tringe, S. G., Izzo, L. K., et al. (2013). Relationship between abundance and specific activity of bacterioplankton in open ocean surface waters. Appl. Environ. Microbiol. 79, 177-184. doi: 10.1128/AEM.02155-12

Janssen, P. H. (2006). Identifying the dominant soil bacterial taxa in libraries of $16 \mathrm{~S}$ rRNA and 16S rRNA genes. Appl. Environ. Microbiol. 72, 1719-1728. doi: 10.1128/AEM.72.3.1719-1728.2006

Jones, S. E., and Lennon, J. T. (2010). Dormancy contributes to the maintenance of microbial diversity. Proc. Natl. Acad. Sci. U.S.A. 107, 5881-5886. doi: 10.1073/pnas.0912765107
Kamke, J., Taylor, M. W., and Schmitt, S. (2010). Activity profiles for marine sponge-associated bacteria obtained by $16 \mathrm{~S}$ rRNA vs $16 \mathrm{~S}$ rRNA gene comparisons. ISME J. 4, 498-508. doi: 10.1038/ismej.2009.143

Kerkhof, L., and Kemp, P. (1999). Small ribosomal RNA content in marine Proteobacteria during non-steady-state growth. FEMS Microbiol. Ecol. 30, 253260. doi: 10.1111/j.1574-6941.1999.tb00653.x

Kindt, R., and Coe, R. (2005). Tree Diversity Analysis. A Manual and Software for Common Statistical Methods for Ecological and Biodiversity Studies. Nairobi: World Agroforestry Centre (ICRAF).

King, A. J., Freeman, K. R., McCormick, K. F., Lynch, R. C., Lozupone, C., Knight, R., et al. (2010). Biogeography and habitat modelling of high-alpine bacteria. Nat. Commun. 1:53. doi: 10.1038/ncomms1055

Kirstine, W. V., and Galbally, I. E. (2012). The global atmospheric budget of ethanol revisited. Atmospheric Chem. Phys. 12, 545-555. doi: 10.5194/acp-12-545-2012

Klappenbach, J. A., Saxman, P. R., Cole, J. R., and Schmidt, T. M. (2001). rrndb: the Ribosomal RNA operon copy number database. Nucleic Acids Res. 29, 181-184. doi: 10.1093/nar/29.1.181

Komagata, K., Iino, T., and Yamada, Y. (2014). "The family acetobacteraceae," in The Prokaryotes SE - 396, eds E. Rosenberg, E. DeLong, S. Lory, E. Stackebrandt, and F. Thompson (Berlin: Springer), 3-78.

Krumins, V., Mainelis, G., Kerkhof, L. J., and Fennell, D. E. (2014). SubstrateDependent rRNA Production in an Airborne Bacterium. Environ. Sci. Technol. Lett. 1, 376-381. doi: 10.1021/ez500245y

Kundu, S., Kawamura, K., Andreae, T. W., Hoffer, A., and Andreae, M. O. (2010). Molecular distributions of dicarboxylic acids, ketocarboxylic acids and $\alpha$-dicarbonyls in biomass burning aerosols: implications for photochemical production and degradation in smoke layers. Atmospheric Chem. Phys. 10, 2209-2225. doi: 10.5194/acp-10-2209-2010

Lanzén, A., Jørgensen, S. L., Bengtsson, M. M., Jonassen, I., Øvreås, L., and Urich, T. (2011). Exploring the composition and diversity of microbial communities at the Jan Mayen hydrothermal vent field using RNA and DNA. FEMS Microbiol. Ecol. 77, 577-589. doi: 10.1111/j.1574-6941.2011.01138.x

Lennon, J. T., and Jones, S. E. (2011). Microbial seed banks: the ecological and evolutionary implications of dormancy. Nat. Rev. Microbiol. 9, 119-130. doi: 10.1038/nrmicro2504

Li, J., Li, N., Li, F., Zou, T., Yu, S., Wang, Y., et al. (2014). Spatial diversity of bacterioplankton communities in surface water of northern South China Sea. PLoS ONE 9:e113014. doi: 10.1371/journal.pone.0113014

Lillis, L., Doyle, E., and Clipson, N. (2009). Comparison of DNA- and ONA-based bacterial community structures in soil exposed to 2,4-dichlorophenol. J. Appl. Microbiol. 107, 1883-1893. doi: 10.1111/j.1365-2672.2009.04369.x

Love, M. I., Huber, W., and Anders, S. (2014). Moderated estimation of fold change and dispersion for RNA-seq data with DESeq2. Genome Biol. 15:550. doi: 10.1186/s13059-014-0550-8

McClure, C. D., Jaffe, D. A., and Gao, H. (2016). Carbon dioxide in the free troposphere and boundary layer at the Mt. bachelor observatory. Aerosol Air Quality Res. 16, 717-728. doi: 10.4209/aaqr.2015.05.0323

McDonald, D., Clemente, J. C., Kuczynski, J., Rideout, J., Stombaugh, J., Wendel, D., et al. (2012). The Biological Observation Matrix (BIOM) format or: how I learned to stop worrying and love the ome-ome. Gigascience 1:7. doi: 10.1186/2047-217X-1-7

Mikkonen, A., Santalahti, M., Lappi, K., Pulkkinen, A.-M., Montonen, L., and Suominen, L. (2014). Bacterial and archaeal communities in long-term contaminated surface and subsurface soil evaluated through coextracted RNA and DNA. FEMS Microbiol. Ecol. 90, 103-114. doi: 10.1111/1574-6941. 12376

Naik, V., Fiore, A. M., Horowitz, L. W., Singh, H. B., Wiedinmyer, C., Guenther, A., et al. (2010). Observational constraints on the global atmospheric budget of ethanol. Atmospheric Chem. Phys. 10, 5361-5370. doi: 10.5194/acp-10-53612010

Oksanen, J., Blanchet, F. G., Kindt, R., Legendre, P., Minchin, P. R., O'Hara, R. B., et al. (2016). vegan: Community Ecology Package. $R$ Package Version 2.3-5. Available at: https://CRAN.R-project.org/package=vegan

Peris-Bondia, F., Latorre, A., Artacho, A., Moya, A., and D'Auria, G. (2011). The active human gut microbiota differs from the total microbiota. PLoS ONE 6:e22448. doi: 10.1371/journal.pone.0022448

Polymenakou, P. N., Mandalakis, M., Stephanou, E. G., and Tselepides, A. (2008). Particle size distribution of airborne microorganisms and pathogens during 
an Intense African dust event in the eastern Mediterranean. Environ. Health Perspect. 116, 292-296. doi: 10.1289/ehp.10684

R Core Team (2016). R: A Language and Environment for Statistical Computing. Vienna: R Foundation for Statistical Computing. Available at: https://www.Rproject.org/

Reponen, T. A., Gazenko, S. V., Grinshpun, S. A., Willeke, K., and Cole, E. C. (1998). Characteristics of airborne actinomycete spores. Appl. Environ. Microbiol. 64, 3807-3812.

Schippers, A., and Neretin, L. N. (2006). Quantification of microbial communities in near-surface and deeply buried marine sediments on the Peru continental margin using real-time PCR. Environ. Microbiol. 8, 1251-1260. doi: 10.1111/j.1462-2920.2006.01019.x

Schostag, M., Stibal, M., Jacobsen, C. S., Bælum, J., Taş, N., Elberling, B., et al. (2015). Distinct summer and winter bacterial communities in the active layer of Svalbard permafrost revealed by DNA- and RNA-based analyses. Front. Microbiol. 6:399. doi: 10.3389/fmicb.2015.00399

Segev, E., Smith, Y., and Ben-Yehuda, S. (2012). RNA dynamics in aging bacterial spores. Cell 148, 139-149. doi: 10.1016/j.cell.2011.11.059

Smith, D. J., Jaffe, D. A., Birmele, M. N., Griffin, D. W., Schuerger, A. C., Hee, J., et al. (2012). Free tropospheric transport of microorganisms from Asia to North America. Microb. Ecol. 64, 973-985. doi: 10.1007/s00248-012-0088-9

Smith, D. J., Timonen, H. J., Jaffe, D. A., Griffin, D. W., Birmele, M. N., Perry, K. D., et al. (2013). Intercontinental dispersal of bacteria and archaea by transpacific winds. Appl. Environ. Microbiol. 79, 1134-1139. doi: 10.1128/AEM.03029-12

Vaïtilingom, M., Charbouillot, T., Deguillaume, L., Maisonobe, R., Parazols, M., Amato, P., et al. (2011). Atmospheric chemistry of carboxylic acids: microbial implication versus photochemistry. Atmospheric Chem. Phys. 11, 8721-8733. doi: 10.5194/acp-11-8721-2011

Vaïtilingom, M., Deguillaume, L., Vinatier, V., Sancelme, M., Amato, P., Chaumerliac, N., et al. (2013). Potential impact of microbial activity on the oxidant capacity and organic carbon budget in clouds. Proc. Natl. Acad. Sci. U.S.A. 110, 559-564. doi: 10.1073/pnas. 1205743110

van Gurp, T. P., McIntyre, L. M., and Verhoeven, K. J. F. (2013). Consistent errors in first strand cDNA due to random hexamer mispriming. PLoS ONE 8:e85583. doi: 10.1371 /journal.pone.0085583

Ventura, M., Canchaya, C., Tauch, A., Chandra, G., Fitzgerald, G. F., Chater, K. F., et al. (2007). Genomics of Actinobacteria: tracing the evolutionary history of an ancient phylum. Microbiol. Mol. Biol. Rev. 71, 495-548. doi: 10.1128/MMBR.00005-07

Vorholt, J. A. (2012). Microbial life in the phyllosphere. Nat. Rev. Microbiol. 10, 828-840. doi: 10.1038/nrmicro2910

Wang, Q., Garrity, G. M., Tiedje, J. M., and Cole, J. R. (2007). Naive Bayesian classifier for rapid assignment of rRNA sequences into the new bacterial taxonomy. Appl. Environ. Microbiol. 73, 5261-5267. doi: 10.1128/AEM. 00062-07

Weiss-Penzias, P., Jaffe, D. A., Swartzendruber, P., Dennison, J. B., Chand, D., Hafner, W., et al. (2006). Observations of Asian air pollution in the free troposphere at Mount Bachelor Observatory during the spring of 2004 . J. Geophys. Res. 111, 1-15. doi: 10.1029/2005JD006522

Wickham, H. (2009). ggplot2: Elegant Graphics for Data Analysis. New York, NY: Springer.

Wilhelm, L., Besemer, K., Fasching, C., Urich, T., Singer, G. A., Quince, C., et al. (2014). Rare but active taxa contribute to community dynamics of benthic biofilms in glacier-fed streams. Environ. Microbiol. 16, 2514-2524. doi: $10.1111 / 1462-2920.12392$

Womack, A. M., Artaxo, P. E., Ishida, F. Y., Mueller, R. C., Saleska, S. R., Wiedemann, K. T., et al. (2015). Characterization of active and total fungal communities in the atmosphere over the Amazon rainforest. Biogeosciences 12, 6337-6349. doi: 10.5194/bg-12-6337-2015

Womack, A. M., Bohannan, B. J. M., and Green, J. L. (2010). Biodiversity and biogeography of the atmosphere. Philos. Trans. R. Soc. Lond. B Biol. Sci. 365, 3645-3653. doi: 10.1098/rstb.2010.0283

Yin, Q., Fu, B., Li, B., Shi, X., Inagaki, F., and Zhang, X.-H. (2013). Spatial variations in microbial community composition in surface seawater from the ultra-oligotrophic center to rim of the South Pacific Gyre. PLoS ONE 8:e55148. doi: 10.1371/journal.pone.0055148

Zhang, Y., Zhao, Z., Dai, M., Jiao, N., and Herndl, G. J. (2014). Drivers shaping the diversity and biogeography of total and active bacterial communities in the South China Sea. Mol. Ecol. 23, 2260-2274. doi: 10.1111/mec. 12739

Zhen, H., Krumins, V., Fennell, D. E., and Mainelis, G. (2015). Development of a dual-internal-reference technique to improve accuracy when determining bacterial 16S rRNA:16S rRNA gene ratio with application to Escherichia coli liquid and aerosol samples. J. Microbiol. Methods 117, 113-121. doi: 10.1016/j.mimet.2015.07.023

Conflict of Interest Statement: The authors declare that the research was conducted in the absence of any commercial or financial relationships that could be construed as a potential conflict of interest.

Copyright (c) 2016 Klein, Bohannan, Jaffe, Levin and Green. This is an open-access article distributed under the terms of the Creative Commons Attribution License (CC BY). The use, distribution or reproduction in other forums is permitted, provided the original author(s) or licensor are credited and that the original publication in this journal is cited, in accordance with accepted academic practice. No use, distribution or reproduction is permitted which does not comply with these terms. 